\title{
Review Article \\ Osteoporotic Hip Fractures: The Burden of Fixation Failure
}

\author{
J. M. Broderick, ${ }^{1}$ R. Bruce-Brand, ${ }^{1}$ E. Stanley, ${ }^{1}$ and K. J. Mulhall ${ }^{1,2,3}$ \\ ${ }^{1}$ Mater Misericordiae University Hospital, Dublin, Ireland \\ ${ }^{2}$ Sports Surgery Clinic, Dublin, Ireland \\ ${ }^{3}$ Cappagh National Orthopaedic Hospital, Dublin, Ireland
}

Correspondence should be addressed to J. M. Broderick; jamesbrod@gmail.com

Received 6 November 2012; Accepted 9 January 2013

Academic Editors: F. Leung, F. Liu, C. Morrey, and C.-W. Oh

Copyright (C) 2013 J. M. Broderick et al. This is an open access article distributed under the Creative Commons Attribution License, which permits unrestricted use, distribution, and reproduction in any medium, provided the original work is properly cited.

\begin{abstract}
Osteoporotic hip fractures are a major cause of morbidity and mortality in the elderly. Furthermore, reduced implant anchorage in osteoporotic bone predisposes towards fixation failure and with an ageing population, even low failure rates represent a significant challenge to healthcare systems. Fixation failure in fragility fractures of the hip ranges from $5 \%$ in peritrochanteric fractures through to $15 \%$ and $41 \%$ in undisplaced and displaced fractures of the femoral neck, respectively. Our findings, in general, support the view that failed internal fixation of these fragility fractures carries a poor prognosis: it leads to a twofold increase in the length of hospital stay and a doubling of healthcare costs. Patients are more likely to suffer a downgrade in their residential status upon discharge with a consequent increase in social dependency. Furthermore, the marked disability and reduction in quality of life evident before salvage procedures may persist at long-term followup. The risk, of course, for the elderly patient with a prolonged period of decreased functioning is that the disability becomes permanent. Despite this, however, no clear link between revision surgery and an increase in mortality has been demonstrated in the literature.
\end{abstract}

\section{Introduction}

Osteoporotic hip fractures are a substantial cause of morbidity and mortality in the elderly. That osteoporosis leads to fragility fractures is well known; however, underlying changes in bone mass and microarchitecture that manifest as fracture in the acute setting can also undermine subsequent attempts at fracture healing. Reduced implant anchorage in osteoporotic bone predisposes towards a failure of fixation [1] and with current projections estimating a worldwide increase in hip fractures from 1.7 million in 1990 to 6.3 million by 2050 [2], even low failure rates represent a significant challenge to healthcare systems. We have reviewed the incidence, the impact, and the additional economic cost of such fixation failures in osteoporotic fractures of the hip.

\section{Review Methods}

2.1. Defining Osteoporotic Fractures. The classic fragility fractures are those of the proximal femur, proximal humerus, distal radius, and vertebral fractures. There are, however, problems in determining what actually constitutes an osteoporotic fracture. The World Health Organization (WHO) defines osteoporosis as a bone mineral density (BMD) of 2.5 standard deviations (SDs) or more below the young normal mean [3]. However, this definition applies only to postmenopausal women assessed by dual-energy X-ray absorptiometry (DEXA) scan and no such definition exists for men. Previous attempts to estimate the degree of osteoporosis include the Singh index, which involves fitting the pattern of proximal femoral trabecular lines into six separate categories; however, this has been shown to have poor inter- and intraobserver reliability [4] and, moreover, it does not correlate with BMD as measured by DEXA scanning. Perhaps the most useful description of fragility fractures is that recently proposed by Kanis et al. [5] in defining osteoporotic fractures as those that occur at a site associated with low BMD and that increase in incidence over the age of 50 years. Indeed, hip fractures alone are regularly used as surrogate markers in determining the international burden of osteoporosis. 
TABLE 1: Incidence of fixation failure and reoperation in undisplaced fractures of the femoral neck (Garden I and II). All patients $>60$ years.

\begin{tabular}{lccccccc}
\hline Study & Year & Fixation method & Mean age & Followup (months) & $n$ & Fixation failure $n(\%)$ & Revision surgery $n(\%)$ \\
\hline Lee et al. [33] & 2008 & MIDHS, SHS, and CS & 72.3 & 12 & 90 & $7(7.8)$ & $7(7.8)$ \\
Bjørgul and Reikerås [12] & 2007 & CS & Nr & 39 & 225 & $37(16.4)$ & $42(18.7)$ \\
Yih-Shiunn et al. [34] & 2007 & SHS, CS & 71.6 & 12 & 84 & $8(9.5)$ & $8(9.5)$ \\
Chiu and Lo [35] & 1996 & Knowles pinning & 73 & 74 & 250 & $42(16.8)$ & $42(16.8)$ \\
Hui et al. [36] & 1994 & SHS & 80 & 6 & 57 & $11(19.2)$ & $10(17.5)$ \\
\hline Total/average & & & & 706 & $105(14.8)$ & $109(15.4)$ \\
\hline
\end{tabular}

Nr: not recorded; CS: cannulated screws; MIDHS: minimally invasive dynamic hip screw; SHS: sliding hip screw.

TABLE 2: Incidence of fixation failure and reoperation in displaced fractures of the femoral neck (Garden III and IV). All patients $>60$ years.

\begin{tabular}{|c|c|c|c|c|c|c|c|}
\hline Study & Year & Fixation method & Mean age & Followup (months) & $n$ & Fixation failure $n(\%)$ & Revision surgery $n(\%)$ \\
\hline Parker et al. [37] & 2010 & CS & 82.2 & 180 & 226 & $95(42)$ & $114(50.4)$ \\
\hline Leonardsson et al. [38] & 2010 & CS, HP & 81.5 & 124 & 217 & $94(43.3)$ & $125(57.6)$ \\
\hline Frihagen et al. [14] & 2007 & CS & 83.2 & 24 & 111 & $46(41.4)$ & $47(42.3)$ \\
\hline Johansson et al. [39] & 2006 & CS & 84 & 24 & 78 & $37(47.4)$ & $34(43.6)$ \\
\hline Blomfeldt et al. [19] & 2005 & CS & 81.4 & 48 & 53 & $22(41.5)$ & $25(47.2)$ \\
\hline Blomfeldt et al. [40] & 2005 & CS & 84 & 24 & 30 & $9(30)$ & $10(33.3)$ \\
\hline Rödén et al. [41] & 2003 & von Bahr screws & 81 & 60 & 53 & $34(64.2)$ & $31(58.5)$ \\
\hline Davison et al. [42] & 2001 & SHS & 73 & 60 & 93 & $30(32.3)$ & $28(30.1)$ \\
\hline Neander et al. [43] & 1997 & CS & 86 & 18 & 10 & $1(10)$ & $1(10)$ \\
\hline Jónsson et al. [44] & 1996 & $\mathrm{HP}$ & 79 & 24 & 24 & $9(37.5)$ & $7(29.2)$ \\
\hline van Vugt et al. [45] & 1993 & SHS & 75.3 & 36 & 21 & $6(28.6)$ & $6(28.6)$ \\
\hline Soreide et al. [46] & 1979 & von Bahr screws & 78 & 12 & 51 & $13(25.5)$ & $11(21.6)$ \\
\hline Total/average & & & & & 967 & $396(41)$ & $439(45.4)$ \\
\hline
\end{tabular}

Nr: not recorded; CS: cannulated screws; HP: hook pin; SHS: sliding hip screw.

2.2. Determinants of the Incidence of Fixation Failure. With multiple fixation devices available and most studies concentrating on one implant versus another, we have included all fixation types in our review. Only studies reporting on patients aged 60 years and older were included.

Fixation failure was defined as

(i) nonunion (alternatively referred to in some studies as early, progressive, or redisplacement of the fracture or fracture collapse),

(ii) avascular necrosis of the femoral head,

(iii) cutout of the implant,

(iv) implant penetration of the femoral head,

(v) "Z-effect",

(vi) breakage of the implant,

(vii) detachment of the implant from the femur,

(viii) intraoperative fracture of the femur and,

(ix) later fracture of the femur.

Only excessive displacement necessitating revision surgery was classified as a fixation failure. Simple migration of the lag screw within the femoral head or a fracture that was noted to have united in "acceptable" varus, valgus, or rotation at routine followup was not classified as a fixation failure. Deep sepsis, despite being an important cause of patient morbidity and failed surgery, also fell outside our search criteria.

Where the number of patients providing data for any outcome was reported, we used these provided data. In studies in which the denominator was unclear, we used the numbers randomised or alive at followup.

2.3. Determinants of the Impact and Cost of Fixation Failure. We attempted to identify studies which specifically recorded final outcome measures in osteoporotic hip fracture patients who suffered a failed fixation. Data was extracted with regard to social and economic implications, namely, length of hospital stay, return to prefracture residential status, quality of life, and functioning as well as economic cost.

\section{Results}

3.1. Incidence of Fixation Failure. Undisplaced femoral neck fractures managed by internal fixation (IF) demonstrate an overall failure rate of $14.8 \%$ and a reoperation rate of $15.4 \%$ (Table 1).

A significantly higher failure rate, however, occurs in displaced fractures of the femoral neck. Randomized controlled trials (RCTs) demonstrate that, overall, a failure rate of $41 \%$ and reoperation rate of $45.4 \%$ can be expected (Table 2 ). 
TABLE 3: Incidence of fixation failure and reoperation in peritrochanteric fractures of the femur. All patients $>60$ years.

\begin{tabular}{|c|c|c|c|c|c|c|c|}
\hline Study & Year & Fixation method & Mean age & $\begin{array}{l}\text { Followup } \\
\text { (months) }\end{array}$ & $n$ & $\begin{array}{c}\text { Fixation } \\
\text { failure } \\
n(\%)\end{array}$ & $\begin{array}{c}\text { Revision } \\
\text { surgery } \\
n(\%)\end{array}$ \\
\hline de Grave* et al. [47] & 2012 & GN, ACE TN & 74.9 & 12 & 112 & $4(3.6)$ & $4(3.6)$ \\
\hline Stern $^{*}$ et al. [48] & 2011 & $\begin{array}{c}\text { SHS, GN, } \\
\text { PFNA, and DHS } \\
\text { Blade }\end{array}$ & 86.4 & 12 & 269 & $11(4.1)$ & $13(4.8)$ \\
\hline $\operatorname{Garg}^{\theta}$ et al. [49] & 2011 & SHS, PFNA & 62.3 & 40 & 81 & $6(7.4)$ & $7(7.4)$ \\
\hline Varela-Egocheaga $^{*}$ et al. [6] & 2009 & PCP, GN & 82 & 12 & 80 & $3(3.8)$ & $\mathrm{Nr}$ \\
\hline Pajarinen $^{*}$ et al. [50] & 2005 & SHS, PFN & 81 & 4 & 108 & $4(3.7)$ & $4(3.7)$ \\
\hline Utrilla* $^{*}$ et al. [51] & 2005 & SHS, TGN & 80 & 12 & 163 & $10(6.2)$ & $5(3.1)$ \\
\hline Papasimos $^{\theta}$ et al. [52] & 2005 & $\begin{array}{c}\text { SHS, PFN, and } \\
\text { TGN }\end{array}$ & 81.2 & 12 & 120 & $12(10)$ & $11(9.2)$ \\
\hline Miedel $^{\theta}$ et al. [53] & 2005 & GN, MSP & 84 & 12 & 217 & $13(6)$ & $12(5.5)$ \\
\hline Saudan $^{*}$ et al. [54] & 2002 & SHS, PFN & 83 & 12 & 168 & $4(2.4)$ & $8(4.8)$ \\
\hline Harrington $^{\theta}$ et al. [55] & 2002 & SHS, IMHS & 83 & 12 & 102 & $6(5.9)$ & $\mathrm{Nr}$ \\
\hline Sadowski ${ }^{\theta}$ et al. [7] & 2002 & $95^{\circ} \mathrm{DCS}, \mathrm{PFN}$ & 79 & 12 & 35 & $8(22.9)$ & $8(22.9)$ \\
\hline Hoffman* and Lynskey [56] & 1996 & SHS, IMHS & 82 & 3.7 & 110 & $4(3.6)$ & $2(1.8)$ \\
\hline Park* et al. [57] & 1998 & SHS, GN & 73 & 18.5 & 60 & $3(5)$ & $1(1.7)$ \\
\hline Hardy ${ }^{*}$ et al. [58] & 1998 & SHS, IMHS & 81 & 12 & 100 & $5(5)$ & $7(7)$ \\
\hline Kukla* et al. [59] & 1997 & SHS, GN & 83 & 6 & 89 & $0(0)$ & $2(2.3)$ \\
\hline Radford* et al. [60] & 1993 & SHS, GN & 80 & 12 & 200 & $18(9)$ & $9(4.5)$ \\
\hline Leung* et al. [61] & 1992 & SHS, GN & 80 & 7 & 186 & $13(7)$ & $6(3.2)$ \\
\hline Total/average & & & & & 2200 & $97(5)$ & $99(4.9)$ \\
\hline
\end{tabular}

Nr: not recorded; GN: Gamma Nail; TN: Trochanteric Nail; SHS: sliding hip screw; PFNA: Proximal Femoral Nail Antirotation; DHS Blade: Dynamic Hip System Blade; PCCP: Percutaneous Compression Plate; PFN: Proximal Femoral Nail; TGN: Trochanteric Gamma Nail; MSP: Medoff Sliding Plate; IMHS: Intramedullary Hip Screw; DCS: Dynamic Condylar Screw.

${ }_{\text {stable fractures only; }}^{*}$ Stable and unstable fracture patterns; ${ }^{\theta}$ unstable fractures only.

With regard to peritrochanteric fractures of the femur, the results of RCTs demonstrate a failure rate of $5 \%$ and reoperation rate of $4.9 \%$ (Table 3 ). Failure rates will vary, however, depending on the stability of the fracture type. While most studies included both stable and unstable fracture patterns, Varela-Egocheaga [6] solely focused on stable fracture types noting a failure rate of $3.8 \%$; this can be contrasted with the findings of Sadowski et al. [7] who investigated only the most unstable fracture patterns (reverse oblique and transverse intertrochanteric) and noted a significant increase in failure rate to $22.9 \%$.

3.2. Impact of Fixation Failure. A hip fracture is probably the most devastating consequence of osteoporosis in our ageing population [8], with the concomitant increase in morbidity and mortality being well documented. Of particular interest, however, is the additional effect any fixation failure will have in this already frail population.

3.2.1. Length of Stay. On average, the failure of fixation results in a twofold increase in the length of hospital stay (Table 4). Thakar et al. [9] divided total hospital stay into acute-and community-stay periods and found that the majority of the 37-day difference in mean total time spent in NHS care for failed fixations was due to an increase in acute hospital bed days rather than community hospital days.

3.2.2. Return to Prefracture Residential Status. Several studies have noted a downgrade in patients' discharge destination following the failure of internal fixation compared to that of uncomplicated cases. Eastwood [10] noted that patients requiring revision surgery were 35 times more likely to be referred to continuing care, with a consequent increase in social dependency. Other studies support these findings with patients less likely to return to their own home and more likely to be referred for continuing rehabilitation $[9,11]$. It appears, however, that this downgrade of residential status is limited to the short term and several authors have noted no difference at long-term followup $[12,13]$.

3.2.3. Quality of Life (QoL) and Functional Outcome. While all patients suffer a decrease in their quality of life after hip fracture, this is particularly evident in patients who have a failed fixation. Tidermark et al. [8] noted that mean quality of life (EQ-5D index score) was higher at each follow-up assessment for those with healing fractures than those who suffered a failure of fixation: at 4 months, 0.66 versus 0.49 $(P<0.05)$ and at 17 months, 0.62 versus $0.31(P<0.005)$. At 
TABLE 4: Impact of fixation failure on length of stay (LOS).

\begin{tabular}{lcccc}
\hline Study & Year & LOS uncomplicated cases (days) & LOS revision cases (days) & Fold change \\
\hline Thakar et al. [9] & 2010 & 30 & 67.1 & 55 \\
Foss et al. [24] & 2007 & 12 & 17 & $\uparrow 2.2$ \\
Sipilä et al. [13] & 2004 & 8 & 31 & $\uparrow 2.1$ \\
Tidermark et al. [62] & 2003 & 17 & 54.4 & $\uparrow 1.8$ \\
Palmer et al. [11] & 2000 & 29.2 & & $\uparrow 1.8$ \\
\hline Average & & & & \\
\hline
\end{tabular}

TABLE 5: Additional cost of fixation failure.

\begin{tabular}{|c|c|c|c|c|c|}
\hline Study & Year & Cost uncomplicated cases & Cost revision cases & Net additional cost & Fold change \\
\hline Thakar et al. [9] & 2010 & $£ 8,976$ & $£ 20,095$ & $£ 11,119$ & $\uparrow 2.2$ \\
\hline Frihagen et al. [63] & 2010 & $€ 33,301$ & $€ 66,388$ & $€ 33,087$ & $\uparrow 2$ \\
\hline Johansson et al. [39] & 2006 & $€ 9,000$ & $€ 18,300$ & $€ 9,300$ & $\uparrow 2$ \\
\hline Rogmark et al. [30] & 2003 & $\$ 12,000$ & $\$ 29,000$ & $\$ 17,000$ & $\uparrow 2.4$ \\
\hline Palmer et al. [11] & 2000 & $£ 5,215$ & $£ 8,676$ & $£ 3461$ & $\uparrow 1.7$ \\
\hline Average & & & & & $\uparrow 2$ \\
\hline
\end{tabular}

inclusion, there had been no difference between the groups. They also noted a more profound decrease in body weight and lean body mass at 6 months in the fixation failure group. Other studies support this additional impact on quality of life in the short term, noting lower QoL scores and increased use of walking aids at 4-6-month followup [13-15].

With regard to long-term outcomes, studies reveal somewhat diverse findings. Frihagen et al. [14] noted that patients with failed IF requiring revision to hemiarthroplasty had worse QoL (Hip Score and Visual Analogue Score) at 4 months, but they did not differ from the healed IF group at 1- and 2-year followup. Similarly, Bjørgul and Reikerås [12] observed no difference at long-term followup in either pain scores or in the proportion of patients retaining their ability to be independent outdoor walkers. In contrast to this, however, several other studies have noted significantly impaired functional outcome and quality of life at one-tofive-year followup. Keating et al. [16], Magaziner et al. [17], and Tidermark [8], all observed that functional outcome for patients managed with IF who did not have subsequent surgery was clearly better than those who required revision surgery at 1-year followup, while Nilsson et al. [18], examining quality of life at 5-year followup via the Nottingham Health Profile (NHP Parts I and II), observed that patients with healed fractures had fewer problems with sleep, housework, and hobbies, and thus functioned better than patients who had required a secondary procedure.

Additionally, it is often assumed that the conversion of a failed IF for either femoral neck or peritrochanteric fractures is a straightforward solution to the problem. Studies, however, that have compared the outcome of primary arthroplasty (either for osteoarthritis or hip fracture) versus revision of failed fixation do not bear this out [14, 19-21]. There is increased surgical difficulty, more complications (with dislocation and infection rates approximately doubled). Functional outcome is also inferior and there is evidence that the survivorship of these revision prostheses is shorter.
There are several reasons for this: patients frequently become profoundly disabled after failed IF leding to more muscle wasting and disuse osteoporosis. Previously operated sites may retain inflammatory tissue or act as a nidus for infection; removal of retained hardware can involve extensive dissection and further damage bone structure, while empty screw holes can lead to inadequate cement pressurisation; fracture collapse may also frustrate attempts at restoration of equal leg lengths.

3.2.4. Mortality. As hip fractures-and their surgical treatment-carry a well-documented increased mortality risk, it is of particular interest to examine the effect of additional surgery in the same patient group. While Thakar et al. [9] did note a significant increase in the probability of mortality following re-operation, other studies have observed only transient increases in mortality during either the initial period of hospitalisation [22] or during the first 6 months [23]. Revision procedures after this did not increase mortality risk and at long-term followup, several authors noted no overall difference in mortality between the groups $[10-13,24,25]$. It is likely, however, that patients passed fit to undergo a secondary operation are a subgroup within this population with a bias towards better survival.

3.2.5. Cost. Table 5 outlines the findings from several studies with regard to the additional cost of fixation failure. While the method of cost assessment and currency differ across studies, a clear trend can be seen with revision surgery for failed IF leading to an overall doubling of costs.

\section{Discussion}

Fragility fractures of the hip, with their well-documented impact on morbidity and mortality, probably represent the 
most devastating outcome of osteoporosis in the elderly. Further complicating management, however, is that weakened osteoporotic bone and vulnerable vascular supply predispose toward a failure of fixation. As our population becomes increasingly older and the incidence of hip fractures continues to rise, even low failure rates will constitute a major challenge to health care systems. Central then to planning for these changes is an understanding of both the incidence of such failures of fixation and the impact they can have.

Overall, the incidence of fixation failure in osteoporotic hip fractures ranges from $5 \%$ in peritrochanteric fractures to $15 \%$ and $41 \%$ in undisplaced and displaced fractures of the femoral neck, respectively. Our findings, in general, support the view that failed internal fixation of these fragility fractures carries a poor prognosis: it leads to a twofold increase in the length of hospital stay and a doubling of healthcare costs. Patients are more likely to suffer a downgrade in their residential status upon discharge with a consequent increase in social dependency. Furthermore, the marked disability and reduction in quality of life evident before salvage procedures may persist at long-term followup. The risk, of course, for the elderly patient with a prolonged period of decreased functioning is that the disability becomes permanent. Despite this, however, no clear link between revision surgery and an increase in mortality has been demonstrated in the literature.

In view of these findings, of particular relevance then is the discussion between IF and arthroplasty in the management of osteoporotic fractures of the hip. While there is a general consensus that elderly patients with an undisplaced (Garden I and II) fracture of the femoral neck can achieve good results after IF with regard to healing, function, and QoL [8, 26], the optimum management of displaced (Garden III and IV) fractures has previously been a source of debate. A recent meta-analysis examining this issue by Parker and Gurusamy [27] noted that although IF was associated with less initial operative trauma when compared to arthroplasty, there was a significantly higher re-operation rate of $40 \%$ versus $11 \%$. Definitive conclusions could not be made regarding the length of hospital stay, return to prefracture residential status, or mortality, but pain and functional outcome did appear to be better for those undergoing a cemented arthroplasty in comparison with fixation. Similar findings were noted by Bhandari et al. in 2003 [28] and Rogmark and Johnell in 2006 [29]. The higher re-operation rate associated with IF is also reflected in studies reporting on financial cost which generally show fixation to be the more expensive option; although IF may have the advantage of a lower initial implant cost, this is outweighed by the high costs associated with repeat admissions and revision surgery [16,30-32]. Reflecting the high failure and re-operation rates observed with IF, the majority of these fractures are managed by arthroplasty in modern orthopaedic practice. For peritrochanteric fractures of the femur, IF remains the mainstay of treatment, current controversy focusing on intra- versus extramedullary devices and cephalic fixation techniques.

In summary, our findings emphasise the importance of optimising patient surgery in order to reduce the incidence of fixation failure and the associated health and social costs. Furthermore, as arthroplasty has become the preferred treatment method for many of these patients, future studies should focus on which arthroplasty would best serve different patient groups.

\section{References}

[1] E. Y. S. Chao, N. Inoue, T. K. K. Koo, and Y. H. Kim, "Biomechanical considerations of fracture treatment and bone quality maintenance in elderly patients and patients with osteoporosis," Clinical Orthopaedics and Related Research, no. 425, pp. 12-25, 2004.

[2] R. G. Cumming, M. C. Nevitt, and S. R. Cummings, "Epidemiology of hip fractures," Epidemiologic Reviews, vol. 19, no. 2, pp. 244-257, 1997.

[3] "Assessment of fracture risk and its application to screening for postmenopausal osteoporosis. Report of a WHO study group," World Health Organization Technical Report Series, vol. 843, pp. $1-129,1994$.

[4] V. C. M. Koot, S. M. M. J. Kesselaer, G. J. Clevers, P. de Hooge, T. Weits, and C. van der Werken, "Evaluation of the Singh index for measuring osteoporosis," The Journal of Bone and Joint Surgery Series B, vol. 78, no. 5, pp. 831-834, 1996.

[5] J. A. Kanis, A. Oden, O. Johnell, B. Jonsson, C. de Laet, and A. Dawson, "The burden of osteoporotic fractures: a method for setting intervention thresholds," Osteoporosis International, vol. 12, no. 5, pp. 417-427, 2001.

[6] J. R. Varela-Egocheaga, R. Iglesias-Colao, M. A. SuárezSuárez, M. Fernández-Villán, V. González-Sastre, and A. Murcia-Mazón, "Minimally invasive osteosynthesis in stable trochanteric fractures: a comparative study between Gotfried percutaneous compression plate and Gamma 3 intramedullary nail," Archives of Orthopaedic and Trauma Surgery, vol. 129, no. 10, pp. 1401-1407, 2009.

[7] C. Sadowski, A. Lübbeke, M. Saudan, N. Riand, R. Stern, and P. Hoffmeyer, "Treatment of reverse oblique and transverse intertrochanteric fractures with use of an intramedullary nail or a $95^{\circ}$ screw-plate: a prospective, randomized study," The Journal of Bone and Joint Surgery Series A, vol. 84, no. 3, pp. 372-381, 2002.

[8] J. Tidermark, "Quality of life and femoral neck fractures," Acta Orthopaedica Scandinavica, Supplementum, vol. 74, no. 309, pp. 1-42, 2003.

[9] C. Thakar, J. Alsousou, T. W. Hamilton, and K. Willett, “The cost and consequences of proximal femoral fractures which require further surgery following initial fixation," The Journal of Bone and Joint Surgery Series B, vol. 92, no. 12, pp. 1669-1677, 2010.

[10] H. D. H. Eastwood, "The social consequences of surgical complications for patients with proximal femoral fractures," Age and Ageing, vol. 22, no. 5, pp. 360-364, 1993.

[11] S. J. Palmer, M. J. Parker, and W. Hollingworth, "The cost and implications of reoperation after surgery for fracture of the hip," The Journal of Bone and Joint Surgery Series B, vol. 82, no. 6, pp. 864-866, 2000.

[12] K. Bjørgul and O. Reikerås, "Outcome after treatment of complications of Gamma nailing: a prospective study of 554 trochanteric fractures," Acta Orthopaedica, vol. 78, no. 2, pp. 231-235, 2007.

[13] J. Sipilä, P. Hyvönen, J. Partanen, J. Ristiniemi, and P. Jalovaara, "Early revision after hemiarthroplasty and osteosynthesis of cervical hip fracture: short-term function decreased, mortality unchanged in 102 patients," Acta Orthopaedica Scandinavica, vol. 75, no. 4, pp. 402-407, 2004. 
[14] F. Frihagen, L. Nordsletten, and J. E. Madsen, "Hemiarthroplasty or internal fixation for intracapsular displaced femoral neck fractures: randomised controlled trial," British Medical Journal, vol. 335, no. 7632, pp. 1251-1254, 2007.

[15] R. Blomfeldt, H. Törnkvist, S. Ponzer, A. Söderqvist, and J. Tidermark, "Displaced femoral neck fracture: comparison of primary total hip replacement with secondary replacement after failed internal fixation: a 2-year follow-up of 84 patients," Acta Orthopaedica, vol. 77, no. 4, pp. 638-643, 2006.

[16] J. F. Keating, A. Grant, M. Masson, N. W. Scott, and J. F. Forbes, "Randomized comparison of reduction and fixation, bipolar hemiarthroplasty, and total hip arthroplasty: treatment of displaced intracapsular hip fractures in healthy older patients," The Journal of Bone and Joint Surgery Series A, vol. 88, no. 2, pp. 249260, 2006.

[17] J. Magaziner, E. M. Simonsick, T. M. Kashner, J. R. Hebel, and J. E. Kenzora, "Predictors of functional recovery one year following hospital discharge for hip fracture: a prospective study," Journals of Gerontology, vol. 45, no. 3, pp. M101-M107, 1990.

[18] L. T. Nilsson, H. Franzen, B. Stromqvist, and I. Wiklund, "Function of the hip after femoral neck fractures treated by fixation or secondary total hip replacement," International Orthopaedics, vol. 15, no. 4, pp. 315-318, 1991.

[19] R. Blomfeldt, H. Törnkvist, S. Ponzer, A. Söderqvist, and J. Tidermark, "Comparison of internal fixation with total hip replacement for displaced femoral neck fractures: randomized, controlled trial performed at four years," The Journal of Bone and Joint Surgery Series A, vol. 87, no. 8, pp. 1680-1688, 2005.

[20] J. C. McKinley and C. M. Robinson, “Treatment of displaced intracapsular hip fractures with total hip arthroplasty: comparison of primary arthroplasty with early salvage arthroplasty after failed internal fixation," The Journal of Bone and Joint Surgery Series A, vol. 84, no. 11, pp. 2010-2015, 2002.

[21] C. Roberts and M. J. Parker, "Austin-Moore hemiarthroplasty for failed osteosynthesis of intracapsular proximal femoral fractures," Injury, vol. 33, no. 5, pp. 423-426, 2002.

[22] L. Kopp, K. Edelmann, P. Obruba, B. Prochazka, K. Blstakova, and V. Dzupa, "Mortality risk factors in the elderly with proximal femoral fracture treated surgically," Acta Chirurgiae Orthopaedicae et Traumatologiae Cechoslovaca, vol. 76, no. 1, pp. 41-46, 2009.

[23] O. Soreide and J. Lillestol, "Mortality patterns following internal fixation for acute femoral neck fractures in the elderly with special emphasis on potential excess mortality following reoperations," Age and Ageing, vol. 9, no. 1, pp. 59-63, 1980.

[24] N. B. Foss, H. Palm, M. Krasheninnikoff, H. Kehlet, and P. Gebuhr, "Impact of surgical complications on length of stay after hip fracture surgery," Injury, vol. 38, no. 7, pp. 780-784, 2007.

[25] S. E. Hoelsbrekken, J. H. Opsahl, M. Stiris, O. Paulsrud, and K. Stromsoe, "Failed internal fixation of femoral neck fractures," Tidsskrift for den Norske laegeforening, vol. 132, no. 11, pp. 13431347, 2012.

[26] J. Tidermark, N. Zethraeus, O. Svensson, H. Törnkvist, and S. Ponzer, "Quality of life related to fracture displacement among elderly patients with femoral neck fractures treated with internal fixation," Journal of Orthopaedic Trauma, vol. 16, no. 1, pp. 34-38, 2002.

[27] M. J. Parker and K. Gurusamy, "Internal fixation versus arthroplasty for intracapsular proximal femoral fractures in adults,"
Cochrane Database of Systematic Reviews, no. 4, Article ID CD001708, 2006.

[28] M. Bhandari, P. J. Devereaux, M. F. Swiontkowski et al., "Internal fixation compared with arthroplasty for displaced fractures of the femoral neck: a meta-analysis," The Journal of Bone and Joint Surgery Series A, vol. 85, no. 9, pp. 1673-1681, 2003.

[29] C. Rogmark and O. Johnell, "Primary arthroplasty is better than internal fixation of displaced femoral neck fractures: a metaanalysis of 14 randomized studies with 2,289 patients," Acta Orthopaedica, vol. 77, no. 3, pp. 359-367, 2006.

[30] C. Rogmark, A. Carlsson, O. Johnell, and I. Sernbo, "Costs of internal fixation and arthroplasty for displaced femoral neck fractures: a randomized study of 68 patients," Acta Orthopaedica Scandinavica, vol. 74, no. 3, pp. 293-298, 2003.

[31] M. J. Parker, R. J. K. Khan, J. Crawford, and G. A. Pryor, "Hemiarthroplasty versus internal fixation for displaced intracapsular hip fractures in the elderly," The Journal of Bone and Joint Surgery Series B, vol. 84, no. 8, pp. 1150-1155, 2002.

[32] T. Johansson, S. A. Jacobsson, I. Ivarsson, A. Knutsson, and O. Wahlstrom, "Internal fixation versus total hip arthroplasty in the treatment of displaced femoral neck fractures: a prospective randomized study of 100 hips," Acta Orthopaedica Scandinavica, vol. 71, no. 6, pp. 597-602, 2000.

[33] Y. S. Lee, S. H. Chen, Y. H. Tsuang, H. L. Huang, T. Y. Lo, and C. R. Huang, "Internal fixation of undisplaced femoral neck fractures in the elderly: a retrospective comparison of fixation methods," Journal of Trauma-Injury, Infection and Critical Care, vol. 64, no. 1, pp. 155-162, 2008.

[34] L. Yih-Shiunn, H. Chien-Rae, and L. Wen-Yun, "Surgical treatment of undisplaced femoral neck fractures in the elderly," International Orthopaedics, vol. 31, no. 5, pp. 677-682, 2007.

[35] F. Y. Chiu and W. H. Lo, "Undisplaced femoral neck fracture in the elderly," Archives of Orthopaedic and Trauma Surgery, vol. 115, no. 2, pp. 90-93, 1996.

[36] A. C. W. Hui, G. H. Anderson, R. Choudhry, J. Boyle, and P. J. Gregg, "Internal fixation or hemiarthroplasty for undisplaced fractures of the femoral neck in octogenarians," The Journal of Bone and Joint Surgery Series B, vol. 76, no. 6, pp. 891-894, 1994.

[37] M. J. Parker, G. Pryor, and K. Gurusamy, "Hemiarthroplasty versus internal fixation for displaced intracapsular hip fractures: a long-term follow-up of a randomised trial," Injury, vol. 41, no. 4, pp. 370-373, 2010.

[38] O. Leonardsson, I. Sernbo, A. Carlsson, K. Akesson, and C. Rogmark, "Long-term follow-up of replacement compared with internal fixation for displaced femoral neck fractures: results at ten years in a randomised study of 450 patients," The Journal of Bone and Joint Surgery Series B, vol. 92, no. 3, pp. 406-412, 2010.

[39] T. Johansson, M. Bachrach-Lindström, P. Aspenberg, D. Jonsson, and O. Wahlström, "The total costs of a displaced femoral neck fracture: comparison of internal fixation and total hip replacement-a randomised study of 146 hips," International Orthopaedics, vol. 30, no. 1, pp. 1-6, 2006.

[40] R. Blomfeldt, H. Törnkvist, S. Ponzer, A. Söderqvist, and J. Tidermark, "Internal fixation versus hemiarthroplasty for displaced fractures of the femoral neck in elderly patients with severe cognitive impairment," The Journal of Bone and Joint Surgery Series B, vol. 87, no. 4, pp. 523-529, 2005.

[41] M. Rödén, M. Schön, and H. Fredin, "Treatment of displaced femoral neck fractures: a randomized minimum 5-year followup study of screws and bipolar hemiprostheses in 100 patients," Acta Orthopaedica Scandinavica, vol. 74, no. 1, pp. 42-44, 2003. 
[42] J. N. S. Davison, S. J. Calder, G. H. Anderson et al., "Treatment for displaced intracapsular fracture of the proximal femur," The Journal of Bone and Joint Surgery Series B, vol. 83, no. 2, pp. 206212, 2001.

[43] G. Neander, P. Adolphson, K. von Sivers, M. Dahlborn, and N. Dalén, "Bone and muscle mass after femoral neck fracture. A controlled quantitative computed tomography study of osteosynthesis versus primary total hip arthroplasty," Archives of Orthopaedic and Trauma Surgery, vol. 116, no. 8, pp. 470-474, 1997.

[44] B. Jónsson, I. Sernbo, A. Carlsson, H. Fredin, and O. Johnell, "Social function after cervical hip fracture. A comparison of hook-pins and total hip replacement in 47 patients," Acta Orthopaedica Scandinavica, vol. 67, no. 5, pp. 431-434, 1996.

[45] A. B. van Vugt, W. M. Oosterwijk, and R. J. A. Goris, "Osteosynthesis versus endoprosthesis in the treatment of unstable intracapsular hip fractures in the elderly: a randomised clinical trial," Archives of Orthopaedic and Trauma Surgery, vol. 113, no. 1, pp. 39-45, 1993.

[46] O. Soreide, A. Molster, and T. S. Raugstad, "Internal fixation versus primary prosthetic replacement in acute femoral neck fractures: a prospective, randomized clinical study," British Journal of Surgery, vol. 66, no. 1, pp. 56-60, 1979.

[47] P. W. de Grave, T. Tampere, P. Byn, J. van Overschelde, C. Pattyn, and R. Verdonk, "Intramedullary fixation of intertrochanteric hip fractures: a comparison of two implant designs. A prospective randomised clinical trial," Acta Orthopaedica Belgica, vol. 78, no. 2, pp. 192-198, 2012.

[48] R. Stern, A. Lubbeke, D. Suva, H. Miozzari, and P. Hoffmeyer, "Prospective randomised study comparing screw versus helical blade in the treatment of low-energy trochanteric fractures," International Orthopaedics, vol. 35, no. 12, pp. 1855-1861, 2011.

[49] B. Garg, K. Marimuthu, V. Kumar, R. Malhotra, and P. P. Kotwal, "Outcome of short proximal femoral nail antirotation and dynamic hip screw for fixation of unstable trochanteric fractures. A randomised prospective comparative trial," HIP International, vol. 21, no. 5, pp. 531-536, 2011.

[50] J. Pajarinen, J. Lindahl, O. Michelsson, V. Savolainen, and E. Hirvensalo, "Pertrochanteric femoral fractures treated with a dynamic hip screw or a proximal femoral nail. A randomised study comparing post-operative rehabilitation," The Journal of Bone and Joint Surgery Series B, vol. 87, no. 1, pp. 76-81, 2005.

[51] A. L. Utrilla, J. S. Reig, F. M. Muñoz, and C. B. Tufanisco, "Trochanteric Gamma nail and compression hip screw for trochanteric fractures: a randomized, prospective, comparative study in 210 elderly patients with a new design of the Gamma nail," Journal of Orthopaedic Trauma, vol. 19, no. 4, pp. 229-233, 2005.

[52] S. Papasimos, C. M. Koutsojannis, A. Panagopoulos, P. Megas, and E. Lambiris, "A randomised comparison of AMBI, TGN and PFN for treatment of unstable trochanteric fractures," Archives of Orthopaedic and Trauma Surgery, vol. 125, no. 7, pp. 462-468, 2005.

[53] R. Miedel, S. Ponzer, H. Törnkvist, A. Söderqvist, and J. Tidermark, "The standard Gamma nail ort he Medoff sliding plate for unstable trochanteric and subtrochanteric fractures. A randomised, controlled trial," The Journal of Bone and Joint Surgery Series B, vol. 87, no. 1, pp. 68-75, 2005.

[54] M. Saudan, A. Lübbeke, C. Sadowski, N. Riand, R. Stern, and P. Hoffmeyer, "Petrochanteric fractures: Is there an advantage to an intramedullary nail? A randomized, prospective study of 206 patients comparing the dynamic hip screw and proximal femoral nail," Journal of Orthopaedic Trauma, vol. 16, no. 6, pp. 386-393, 2002.

[55] P. Harrington, A. Nihal, A. K. Singhania, and F. R. Howell, "Intramedullary hip screw versus sliding hip screw for unstable intertrochanteric femoral fractures in the elderly," Injury, vol. 33 , no. 1, pp. 23-28, 2002.

[56] C. W. Hoffman and T. G. Lynskey, "Intertrochanteric fractures of the femur: a randomized prospective comparison of the Gamma nail and the Ambi hip screw," Australian and New Zealand Journal of Surgery, vol. 66, no. 3, pp. 151-155, 1996.

[57] S. R. Park, J. S. Kang, H. S. Kim, W. H. Lee, and Y. H. Kim, "Treatment of intertrochanteric fracture with the Gamma AP locking nail or by a compression hip screw-a randomised prospective trial," International Orthopaedics, vol. 22, no. 3, pp. 157-160, 1998.

[58] D. C. R. Hardy, P. Y. Descamps, P. Krallis et al., "Use of an intramedullary hip-screw compared with a compression hipscrew with a plate for intertrochanteric femoral fractures: a prospective, randomized study of one hundred patients," The Journal of Bone and Joint Surgery Series A, vol. 80, no. 5, pp. 618630, 1998.

[59] C. Kukla, T. Heinz, G. Berger, O. Kwasny, A. Rosenberger, and V. Vécsei, "Gamma nail versus dynamic hip screw in 120 patients over 60 years-a randomized trial," Acta Chirurgica Austriaca, vol. 29, no. 5, pp. 290-293, 1997.

[60] P. J. Radford, M. Needoff, and J. K. Webb, "A prospective randomised comparison of the dynamic hip screw and the gamma locking nail," The Journal of Bone and Joint Surgery Series B, vol. 75, no. 5, pp. 789-793, 1993.

[61] K. S. Leung, W. S. So, W. Y. Shen, and P. W. Hui, "Gamma nails and dynamic hip screws for peritrochanteric fractures: a randomised prospective study in elderly patients," The Journal of Bone and Joint Surgery Series B, vol. 74, no. 3, pp. 345-351, 1992.

[62] J. Tidermark, S. Ponzer, O. Svensson, A. Söderqvist, and H. Törnkvist, "Internal fixation compared with total hip replacement for displaced femoral neck fractures in the elderly. A randomised, controlled trial," The Journal of Bone and Joint Surgery Series B, vol. 85, no. 3, pp. 380-388, 2003.

[63] F. Frihagen, G. M. Waaler, J. E. Madsen, L. Nordsletten, S. Aspaas, and E. Aas, "The cost of hemiarthroplasty compared to that of internal fixation for femoral neck fractures: 2-year results involving 222 patients based on a randomized controlled trial," Acta Orthopaedica, vol. 81, no. 4, pp. 446-452, 2010. 


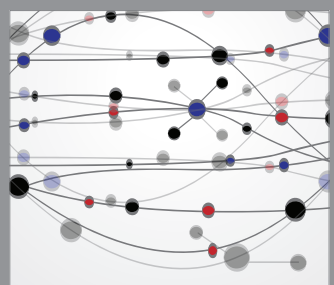

The Scientific World Journal
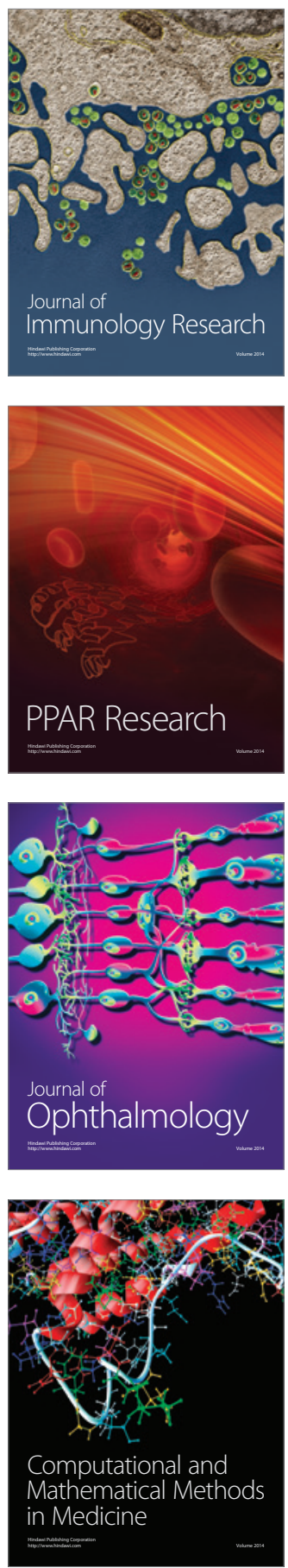

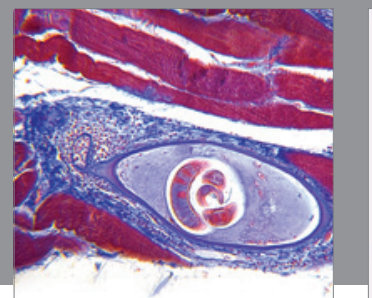

Gastroenterology

Research and Practice
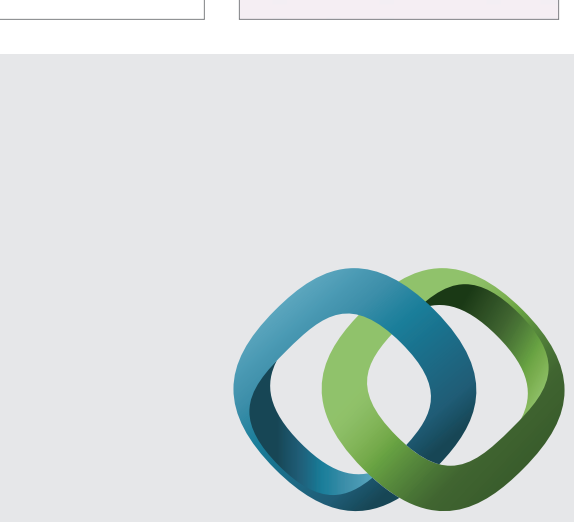

\section{Hindawi}

Submit your manuscripts at

http://www.hindawi.com
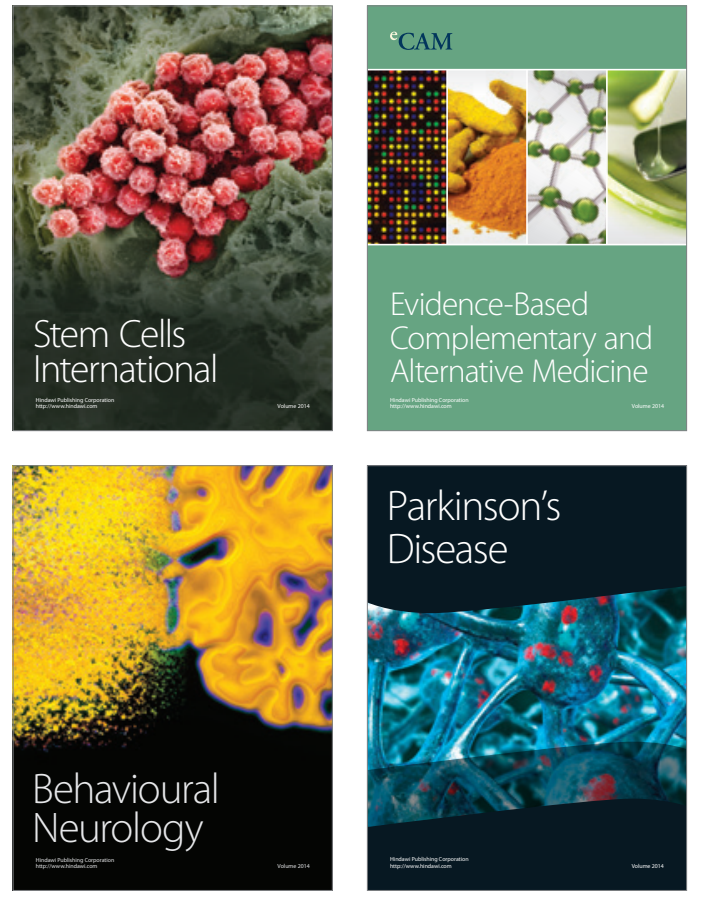
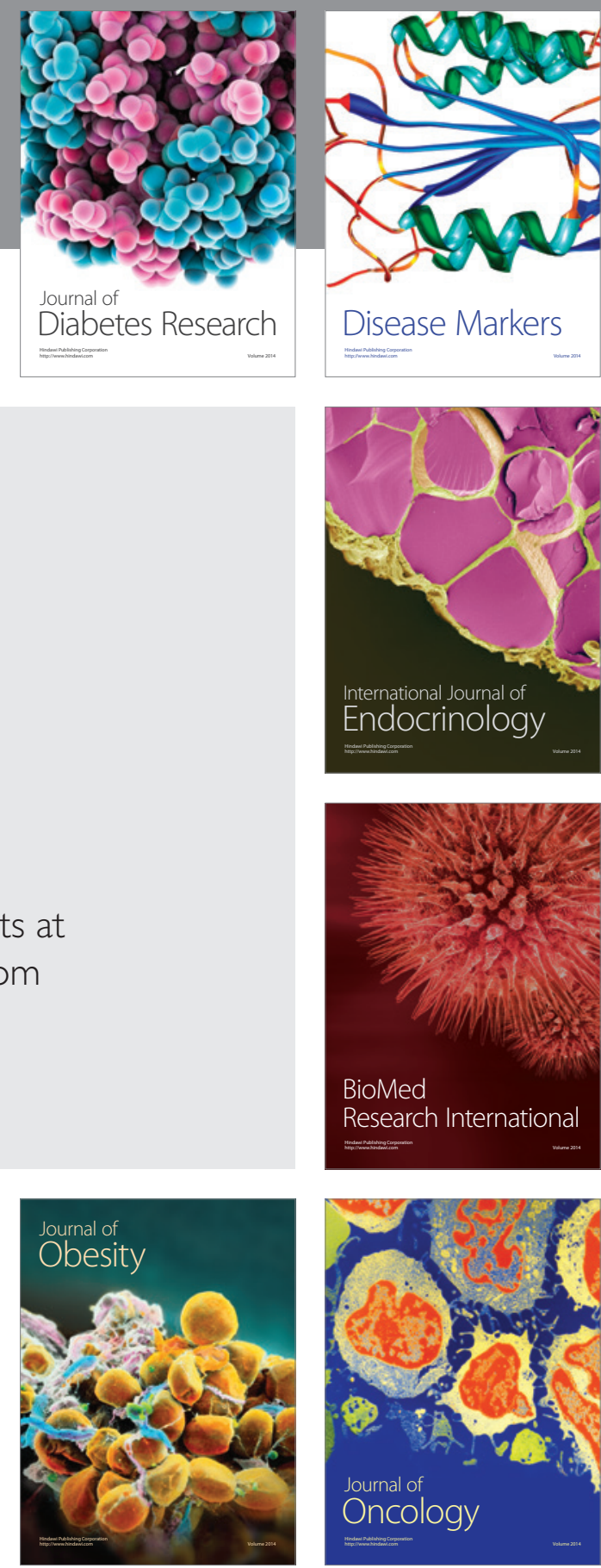

Disease Markers
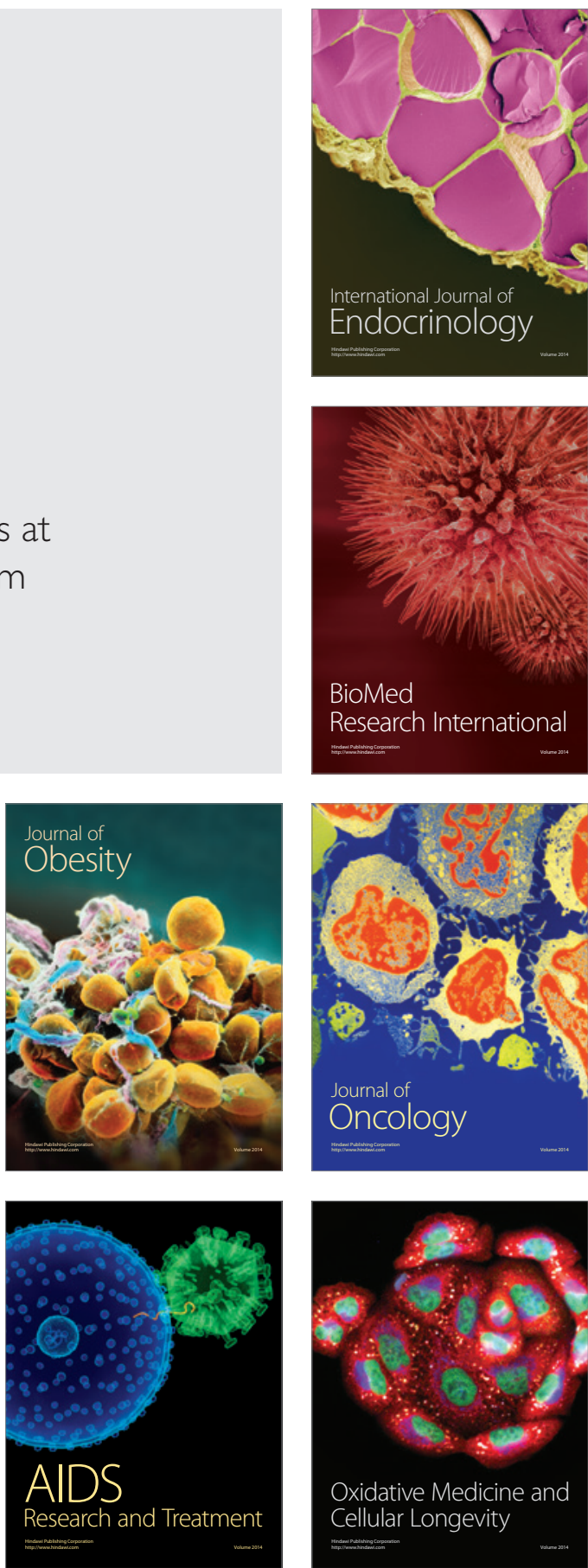